\title{
Behavioral Electrophysiology of Psychostimulants
}

\author{
George V Rebec*,I \\ 'Program in Neuroscience, Department of Psychological and Brain Sciences, Indiana University, Bloomington, IN, USA
}

\begin{abstract}
The motor-activating effects of amphetamine and other psychostimulants such as cocaine depend on an increase in dopamine (DA) transmission in the striatum, a key component of the basal ganglia and the forebrain motive circuit. This review focuses on research aimed at using electrophysiological techniques — including extracellular unit recording and iontophoresis - in alert, fully functioning animals to understand how these drugs alter striatal neuronal processing under behaviorally relevant conditions. The data indicate that DA works in conjunction with glutamate (GLU), an excitatory amino acid, to enhance the signal-to-noise ratio of afferent information. This DA-GLU interaction appears to play a critical role in the amphetamine-induced activation of striatal neurons. The pattern of striatal activation, moreover, changes as the behavioral response changes from unfocused locomotion to highly focused, stereotyped behavior, but interestingly, the striatal response pattern is not reflected in substantia nigra reticulata, a primary target of striatal efferents. Although cocaine also activates striatal neurons during behavior, the underlying mechanisms appear to be complicated by factors unique to this drug and deserve further evaluation. Collectively, these findings provide unique insight into the neuronal processes by which the striatum participates in psychostimulant-induced motor behavior.

Neuropsychopharmacology (2006) 3 I, 234 I-2348. doi:I 0. I038/sj.npp. I 30 I I60; published online 19 July 2006
\end{abstract}

Keywords: amphetamine; cocaine; dopamine; glutamate; stereotypy; striatum

\section{INTRODUCTION}

As psychostimulants, cocaine, amphetamine, and a variety of amphetamine derivatives heighten arousal, increase behavioral activation, and harbor the potential for abuse. Identifying the neuronal substrates of these effects is a key goal of psychostimulant research. In pursuit of this goal, many investigators have focused on the mesotelencephalic dopamine (DA) system and its forebrain targets, including dorsal and ventral striatum, prefrontal cortex, and other regions of a broadly defined corticolimbic system (eg, Pierce and Kumaresan, 2006). As part of the so-called motive circuit, these structures and their DA input are critically involved in setting patterns of motor activity, aimed at acquiring food, sex, and other natural reinforcers (Mogenson et al, 1993). By acting directly on the DA system, psychostimulants appear to gain control of behavior by usurping motive-circuit operations. The neuronal substrates of this effect, however, remain elusive. It is important, therefore, to understand how motive-circuit neurons respond to cocaine and amphetamine in a behavioral context and to determine how these drugs alter

\footnotetext{
* Correspondence: Dr GV Rebec, Program in Neuroscience, Department of Psychological and Brain Science, Indiana University, IIOI E. IOth Street, Bloomington, IN 47405-7007, USA, Tel: + I 812855 4832, Fax: + I 812855 4520, E-mail: rebec@indiana.edu

Received 13 January 2006; revised 23 February 2006; accepted I March 2006

Online publication: 9 June 2006 at http://www.acnp.org/citations/ Npp060906060027/default.pdf
}

the synaptic action of DA and, in turn, the action of other transmitters under behaviorally relevant conditions. An increasing number of studies have begun to address these and related issues by applying electrophysiological recording techniques to behaving animals. When combined with iontophoresis or intracerebral infusions, this approach can also provide unique insight into how drugs and transmitters interact to process behaviorally relevant information.

This review focuses on what this line of research has revealed about the role of striatal neurons in processing the characteristic patterns of repetitive or stereotyped movement that occur in rats treated with cocaine or amphetamine. In humans, these psychostimulant-induced motor patterns occur simultaneously with perseverative thought processes that closely resemble some forms of psychosis (Segal and Janowsky, 1978). The striatum appears to play a key role because of circuitry that integrates both sensorimotor and motivational information for behavioral output. The neurophysiology of other motive-circuit structures in the rewarding and addictive properties of psychostimulants are reviewed elsewhere (Carelli, 2004; Porrino and Lyons, 2000; Rebec and Sun, 2005; Woodward et al, 2000).

\section{STRIATAL ORGANIZATION AND OPERATION}

Despite a relatively homogeneous appearance in conventional histological preparations, the striatum is often divided into dorsal and ventral components. Although both share a similar cytoarchitecture, they differ to some extent in the topography of their afferent and efferent connections. 
Dorsal striatum, which is associated with the classic extrapyramidal motor system, forms the neostriatum or main part of the caudate-putamen complex (Parent and Hazrati, 1995). Ventral striatum, in contrast, includes the nucleus accumbens (NAcc), which has been described as a 'gateway' or 'interface' allowing limbic structures access to the motor system (Groenewegen et al, 1996). Although these striatal regions may indeed serve different aspects of behavior, they share an anatomy characterized by overlapping connections embedded in an array of compartments and subterritories (Heimer et al, 1995).

\section{Major Afferent Connections}

Together, dorsal and ventral striatum receive input from the entire cortical mantle. Dorsal striatum receives this input mainly from sensorimotor, auditory, and visual areas of neocortex, whereas input to ventral striatum arises from allocortical and mesocortical areas as well as from the 'cortical-like' basolateral amygdaloid complex (McGeorge and Faull, 1989). Within this overall topography, there is a complex regional organization. Corticostriatal input, for example, terminates in longitudinal bands, and reciprocally interconnected cortical areas terminate in adjacent or interdigitating striatal zones (Selemon and Goldman-Rakic, 1985). Cortical projections may also show varying degrees of convergence and divergence. In the neostriatum, for example, a single cortical area may project to more than one region, and similarly, each region may receive input from more than one cortical area (Flaherty and Graybiel, 1991). Such an arrangement allows for the integration of widespread cortical information.

Electrical stimulation of corticostriatal fibers elicits shortlatency activation of striatal target neurons (Wilson, 1993). This effect appears to be mediated by glutamate (GLU), an excitatory amino acid released by corticostriatal terminals (Parent et al, 1995). Excitatory GLU afferents also arise from midline thalamus, and like corticostriatal fibers, they terminate on the heads of dendritic spines (Smith and Bolam, 1990). Interestingly, however, cortical and thalamic afferents do not typically converge on the same neurons.

Although GLU fibers, especially those of cortical origin, provide massive input to the striatum, the most thoroughly studied afferent system originates in the midbrain. The mesostriatal DA pathway arises from a continuous collection of cells in the substantia nigra compacta $(\mathrm{SNc})$ and ventral tegmental area (VTA) (Le Moal, 1995). Their axons, which are thin and unmyelinated, project ipsilaterally and undergo extensive collateralization. Branching DA collaterals account for $>20 \%$ of all striatal axon terminals. These fibers typically form en passant contacts with the same target cells that receive GLU input, but the DA projection is localized to dendritic spine shafts, putting it $<2 \mu \mathrm{m}$ from GLU terminals on spine heads. Moreover, a single DA fiber may make multiple contacts along a single dendrite as well as with dendrites of multiple target cells (Smith and Bolam, 1990). Thus, a single DA neuron can influence many cortical inputs.

Despite their diffuse innervation pattern, DA fibers follow a distinct topography. Dorsal striatum receives DA fibers primarily from ventral and intermediate layers of the $\mathrm{SNc}$, whereas DA input to ventral striatum arises from dorsal and intermediate layers of the VTA as well as from medial SNc
(Le Moal, 1995). This topographical organization is reinforced by apparent differences in the regulation of striatal DA transmission. Heterogeneities in the DA transporter, for example, allow for significantly faster removal of extracellular DA in dorsal than in ventral striatum (Garris and Rebec, 2002). This difference may be relevant to evidence that striatal DA participates in a form of 'volume transmission', in which the signaling molecule may travel $>10 \mu \mathrm{m}$ from its release site (Wightman and Zimmerman, 1990).

\section{Information Outflow}

The target cells of both GLU and DA afferents are medium spiny neurons, which account for $90-95 \%$ of the neuronal population of the striatum (Groves, 1983). Before leaving the striatum, their axons form extensive collateral networks within or near the dendritic arbor of the cell of origin, indicating important local circuit functions. In rats, medium spiny neurons from dorsal striatum project heavily to targets in globus pallidus (GP) and substantia nigra reticulata $(\mathrm{SNr})$ with a smaller projection to entopeduncular nucleus (Heimer et al, 1995). Some striatofugal fibers also reach DA neurons either by sending direct projections to SNc and VTA or by contacting DA dendrites in SNr. These dendrites, which arise from DA neurons in ventral SNc, not only allow the striatum to influence DA activity, but because of dendritic DA release (Groves et al, 1975), they also allow DA to modulate the striatonigral influence in SNr (Martin and Waszczak, 1996). Interestingly, the efferent system of ventral striatum not only targets ventral pallidum but also $\mathrm{SNc}, \mathrm{SNr}$, and VTA, thus providing ventral influence on dorsal striatal circuits (Groenewegen et al, 1993). Ventral striatal projections also reach the extended amygdala, lateral hypothalamus, and pontine reticular formation.

The main transmitter in the entire medium spiny projection system is $\gamma$-amino-butyric acid (GABA), which is known to exert a strong inhibitory effect (Kita et al, 2004; Tepper et al, 2004). Activation of striatopallidal or striatonigral neurons, for example, inhibits neuronal activity in GP or $\mathrm{SNr}$, respectively. These projections are themselves subject to additional intrinsic and extrinsic regulation. Further connections along this circuit include 'downstream' links to the pedunculopontine nucleus and 'upstream' projections to motor thalamus. This classic circuitry, especially the connection with motor thalamus, is thought to play a key role in movement (DeLong, 1990). Ventral striatal outflow to ventral pallidum, in contrast, innervates mediodorsal thalamus. This thalamic nucleus is reciprocally related to prefrontal cortex, suggesting that ventral striatal outflow is concerned primarily with the cognitive, emotional, or regulatory aspects of behavior rather than motor inhibition or initiation (Le Moal, 1995).

As the limbic-motor interface, the NAcc is divided into a central core surrounded on its lateral, medial, and ventral aspects by a peripheral shell (Pennartz et al, 1994). Both subterritories share some characteristic ventral striatal afferent and efferent connections, but shell is noted for projections to extended amygdala and lateral hypothalamus, whereas core may exert a more direct influence on cortical processing of motor activity via more typical extrapyramidal connections. NAcc core-shell distinctions have also been 
made at the neurophysiological (Uzwiak et al, 1997; Wood and Rebec, 2004) and neurochemical levels (Rebec et al, 1997a) in behaving rats. If, as ample evidence suggests (see Groenewegen et al, 1993), NAcc shell processes limbicrelated information having little direct access to primary motor pathways, the DA innervation of this region may be uniquely adapted to this processing role.

\section{FUNCTIONAL ACTIVITY OF STRIATAL NEURONS}

One of the most striking features of striatal neurons is their relatively low level of spontaneous activity. Discharge rates of $<6$ spikes/s interrupted by periods of complete silence are typically reported for both in vitro and in vivo preparations (Calabresi et al, 1987; Wilson, 1993). Even awake, unrestrained animals have a low or silent level of unit activity in dorsal and ventral striatum during quiet rest. In fact, a systematic analysis of unit activity in alert but quietly resting rats suggests that $>70 \%$ of striatal neurons are silent (Sandstrom and Rebec, 2003). In view of the large number of medium spiny neurons relative to other striatal cell types, it seems reasonable to conclude that slow-firing or silent units correspond to the medium spiny population. Intracellular staining of neurons recorded both intra- and extracellularly supports this conclusion (Wilson and Groves, 1981). Subsequent intracellular-labeling studies have shown that a small group of tonically active striatal neurons, many of which have firing rates $>10$ spikes/s, correspond to a small population of aspiny interneurons (Chang and Wilson, 1990).

The relatively low level of medium spiny activity reflects the dominance of an inwardly rectifying potassium current that keeps the membrane hyperpolarized (Wilson, 1993). Episodes of firing are the result of maintained plateau depolarizations, which are driven by afferent input (Wilson and Kawaguchi, 1996). Interestingly, however, inward rectification is present on the dendrites, making these cells relatively insensitive to individual excitatory events or uncoordinated input activity. Only when afferent excitation arrives in a coordinated manner, causing depolarization over a relatively large area of the dendritic tree, can sufficient charge reach the cell body to overcome the barrier of inward rectification. At this point, individual inputs, arriving within the context of a coordinated afferent excitation, become more likely to generate spike activity. This model of medium spiny neurons suggests that the temporal pattern of spikes in these units is not a faithful representation of spike activity in a particular afferent fiber, but rather reflects an envelope of afferent activity integrated over periods of $100 \mathrm{~ms}$ or longer (Mink, 1996). A further implication is that a change in the level of inhibitory input plays a relatively small role in the transition to a depolarized state. Thus, intrastriatal inhibitory networks, which include GABA collaterals from neighboring medium spiny units, may not be critical for setting the level of spontaneous activity but could be important for coordinating interactions among adjacent neurons during episodes of firing.

\section{Behavior-Related Information Processing}

In primates trained to make discrete movements in response to a sensory cue, most striatal neurons increase discharge rate (DeLong, 1990). Detailed analysis of the firing patterns of these neurons has revealed that despite the correlation with movement, the actual role of these units in behavior seems relatively complex. Some striatal neurons, for example, fire preferentially in relation to a limb movement triggered by a cue, whereas others respond only with respect to spontaneous movements (Kimura, 1990). Similarly, saccade-related activity recorded from primates differs when saccades are made under memory-guided $v s$ visually guided conditions (Hikosaka et al, 1989). A sensory stimulus, moreover, may initiate a change in firing rate only when the stimulus is behaviorally significant, and in ventral striatum, many neurons also have place- and reward-related firing patterns (Apicella et al, 1991). Thus, rather than signal simple motor or sensory events, striatal neurons appear to convey context-dependent information representing processes related to selective attention, reinforcement, or other complex functions. Changes in striatal activity, therefore, may represent a mechanism by which such functions gain access to motor output.

Although relatively few studies have assessed the behavioral response properties of striatal neurons in rats, the available data suggest a similar complexity (Aldridge et al, 1993). Neuronal responses to discrete movements are common in extreme dorsolateral striatum, which, like primate putamen, receives preferential input from sensorimotor cortex (Carelli and West, 1991; West et al, 1990). Rat striatal neurons have also been reported to alter firing rate in association with sensory-triggered movements much like that reported for primates (Gardiner and Kitai, 1992; West et al, 1990). Many of these neuronal responses, moreover, depend on the behavioral context in which they occur (eg, a change in firing rate to a sensory-triggered movement may not occur when the movement occurs outside the task). These data confirm a convergence of sensory and motor signals in rat striatum, suggesting that striatal neurons serve an important integrative role.

\section{Behavior-Related Transmitter Interactions}

DA appears to act as a gain-enhancing neuromodulator by facilitating the excitatory action of GLU released by striatal afferents (Servan-Schreiber et al, 1990). In a direct test of this hypothesis in conscious, unrestrained rats, we recorded striatal unit activity and applied DA and GLU iontophoretically (Pierce and Rebec, 1995). Whereas GLU caused a frank, dose-dependent activation of all recorded units, DA was weakly excitatory or inhibitory. When both substances were applied simultaneously, the excitatory actions of GLU were enhanced, suggesting that DA increases the strength of the GLU signal. We followed up on this conclusion with a detailed assessment of DA-GLU interactions (Kiyatkin and Rebec, 1996). DA (5-80 nA) was applied for prolonged periods (2-3 min) and brief applications of GLU (5-40 nA; $15 \mathrm{~s}$ ) were made before, during, and after DA iontophoresis. The result was an overall enhancement of the GLU response relative to the DA-induced change. Collectively, these findings indicate that DA has the net effect of amplifying the phasic activation induced by GLU; this effect, moreover, is apparent in relation to the level of background firing. Thus, DA enhances the relative rather than absolute strength of the GLU signal. Further testing revealed that 
endogenous DA exerts this effect mainly via D1 receptors (Kiyatkin and Rebec, 1999b). In fact, with D1 receptor blockade, striatal neurons become hyper-responsive to GLU. It appears, therefore, that a primary function of DA release, which is triggered by behaviorally relevant stimuli, is to restrain the absolute magnitude of the GLU response while enhancing its relative strength. By coinciding with the arrival of cerebrocortical information, DA release ensures the controlled flow of this information to relevant neurobehavioral circuits.

The excitatory action of GLU is also regulated by GABA. In alert rats, both spontaneously active and GLU-stimulated striatal neurons are GABA-sensitive. In fact, most units show short-latency inhibitions to leakage of GABA from the iontophoresis pipette $(0 \mathrm{nA})$ and the response progresses to complete silence with a small increase (10-20 nA) in ejection current (Kiyatkin and Rebec, 1999a). Under natural conditions, therefore, the activity of striatal neurons, and thus their integrative functions, depends on a GLU-GABA balance, which is regulated further by DA release.

\section{NEURAL SUBSTRATES OF PSYCHOSTIMULANT- INDUCED CHANGES IN MOTOR ACTIVATION}

The motor-activating effects of amphetamine include species-specific forms of investigative behavior, which in the rat are manifest as locomotion and rearing as well as head bobbing and sniffing (Rebec and Bashore, 1984). Expression of these behaviors follows a complex, dosedependent pattern. At relatively low doses, behavioral activation occurs over a large area. As doses increase, a constricted form of stereotypy emerges in which an early phase of locomotion and rearing gives way to a phase of highly focused head bobbing, sniffing, and occasional oral behavior. Although ample evidence implicates striatal DA release in these dose-dependent effects, this mechanism by itself explains neither the appearance of specific behaviors nor the overall pattern of the response, including the transition from unfocused behavioral activation to episodes of focused stereotypy (Segal and Kuczenski, 1994).

\section{Amphetamine Effects on Striatal Neurons}

Procedures designed to monitor amphetamine-induced changes in neuronal activity in ambulant animals are beginning to shed light on the striatal substrates of the motor-activating effects of amphetamine. Early reports, based on the records of striatal multiple-unit activity in behaving rats, indicated a relatively homogeneous, dosedependent increase to amphetamine (Hansen and McKenzie, 1979). Although this effect correlates with increases in striatal DA transmission, single-unit data indicate a relatively complex striatal response. At a dose that induces unfocused motor activation $(1.0 \mathrm{mg} / \mathrm{kg} d$ amphetamine), neurons that change activity in close temporal association with movement are excited, but neuronal activity unrelated to movement is inhibited (Haracz et al, 1993; West et al, 1997). In either case, DA receptor antagonists reverse the neuronal response, supporting a role for DA in both the excitation and inhibition (Rosa-Kenig et al, 1993). DA, however, is not the sole mediator of the excitation because this response, and not the inhibition, is also attenuated by cerebrocortical ablations (Tschanz et al, 1994). Because these ablations remove most GLU input from striatum, it appears that GLU underlies at least some of the striatal effects of amphetamine. Specifically, DA may facilitate a GLU excitation of motor-related units, whereas the inhibition of non-motorrelated activity may reflect an action of DA on neurons that receive weak GLU input (Haracz et al, 1998).

Application of amphetamine directly to striatal neurons provides some support for this hypothesis, but also underscores the difficulty of interpreting the neuronal substrates of the behavioral response to systemic drug injections. When amphetamine is applied iontophoretically to striatal neurons in conscious, quietly resting rats, the vast majority of units respond with a dose-dependent (5-40 nA) inhibition (Kiyatkin and Rebec, 1997). DA antagonists block this effect confirming that when cerebrocortical input is relatively weak, which is most likely the case under resting conditions, the amphetamine-induced inhibition involves DA. Interestingly, prolonged amphetamine iontophoresis (5-30 nA; 2-3 min) also inhibited GLU-evoked excitations; in fact, $\geqslant 20 \mathrm{nA}$ amphetamine caused a complete block of the GLU response. In this case, however, iontophoretic amphetamine did not mimic the action of iontophoretic DA, which has the net effect of enhancing the GLU signal (see above). It is possible that amphetamine has a much stronger action than DA when applied directly to neurons because although iontophoretic DA may act postsynaptically, iontophoretic amphetamine is likely to increase DA transmission at all affected synaptic terminals and thus overwhelms any GLU-evoked effect. This view is consistent with the evidence that when applied to NAcc slices, amphetamine attenuates cortically evoked excitations (Nicola et al, 1996). In sum, the data suggest that amphetamine-induced striatal inhibitions reflect an increase in DA transmission, whereas excitations, which are likely to occur with systemic amphetamine administration, result from a DA interaction with cerebrocortical GLU release.

A thorough characterization of well-isolated, single units recorded in the striatum indicate that $1.0 \mathrm{mg} / \mathrm{kg} d$ amphetamine activates $\sim 80 \%$ of the neuronal population (see Rebec, 1998). Interestingly, this pattern breaks down as the dose increases. At $5.0 \mathrm{mg} / \mathrm{kg}$, which induces a phase of focused stereotypy, several different neuronal response patterns emerge (Rebec et al, 1997b; Ryan et al, 1989). Whereas some striatal neurons continue to show either a simple activation or inhibition throughout the drug response, an increasing number become inhibited during the onset of focused stereotypy. The net result is a more focused neuronal activation pattern that may underlie the transition to a more focused motor response.

\section{Amphetamine Effects in $\mathrm{SNr}$}

Perhaps the most important striatal target in rats is $\mathrm{SNr}$, which receives both direct and indirect projections from the striatum and then routes this information to thalamic as well as descending nuclei. The SNr is dominated by GABAcontaining projection cells interspersed with clusters of DA neurons and perhaps a small number of GABA- or peptidecontaining interneurons (Juraska et al, 1977). GABA and, to 
some extent, DA and GLU appear to play a critical role in regulating the activity of $\mathrm{SNr}$ neurons. These cells are characterized by short biphasic spikes, a tonic level of spontaneous activity, and a sensitivity to depolarizing currents that permits repetitive firing up to 200 spikes/s. $\mathrm{SNr}$ units are inhibited by electrical stimulation of the striatum or by GABA iontophoresis (Deniau et al, 1978; Waszczak and Walters, 1983), implicating GABA in the main striatal control of $\mathrm{SNr}$ projection neurons. Relatively little information is available, however, on $\mathrm{SNr}$ function during behavior. A classical view predicts a high level of $\mathrm{SNr}$ basal activity that declines during movement. The implication is that tonically active inhibitory $\mathrm{SNr}$ outputs normally keep 'downstream' movement generators in check to suppress inappropriate behavior. Movement would be expected to correlate with a reduction in this tonic rate. Although some evidence supports this model, recent data indicate a complex picture in which $\mathrm{SNr}$ neuronal activity plays a role in the focal selection of desired motor mechanisms and the inhibition of others (Gulley et al, 2002b; Shi et al, 2004). In fact, both increases and decreases have been reported to occur in SNr during an operant task. In a detailed study of $\mathrm{SNr}$ activity, Hikosaka et al (1993) reported task-related changes in neuronal activity to a wide range of stimuli, including the expectation of reward.

If the neuronal patterns established in the striatum are critically involved in shaping the motor response to amphetamine, then one might expect some aspect of these patterns to be manifest in SNr. Yet, we recorded from $\mathrm{SNr}$ in ambulant rats and found no simple relationship to firing patterns in the striatum (Gulley et al, 2004). During periods of spontaneous movement before drug injection, for example, $\mathrm{SNr}$ activity was largely unchanged relative to periods of quiet rest. We also reported a similar result after an analysis of $\mathrm{SNr}$ activity in rats performing an operant response for sucrose reward (Gulley et al, 2002b); in fact, only discrete motor acts such as head turning elicited a neuronal response and only in a limited number of units. Thus, unlike many striatal neurons, which appear to be sensitive to a general level of motor activation, units in $\mathrm{SNr}$ are often tuned to discrete movements. Thus, movement-related changes in the striatum may not have an obvious correlate in SNr. Although this is surprising given that $>80 \%$ of striatal neurons project to $\mathrm{SNr}$ or GP (Parent and Hazrati, 1995), data from stimulation experiments support this conclusion. For example, fewer than half the units recorded in SNr of behaving primates are altered after electrical stimulation of the striatum (Hikosaka et al, 1993). It is also the case that a systemic injection (subcutaneous (s.c.)) of either a low or high dose of amphetamine ( 1.0 or $5.0 \mathrm{mg} / \mathrm{kg} d$-amphetamine) failed to elicit a consistent $\mathrm{SNr}$ response (Gulley et al, 2004). We recorded neurons that were excited, inhibited, or showed no change despite distinct dose-dependent patterns of motor activity. To assess the striatal contribution to these effects in $\mathrm{SNr}$, some animals received amphetamine directly into the striatum at a behaviorally activating dose. Again, however, no consistent neuronal pattern emerged in $\mathrm{SNr}$. In fact, the most common effect in $\mathrm{SNr}$, recorded in $47 \%$ of sampled units, was no change in firing from the preinfusion baseline rate. Thus, widespread changes in striatal activity that occur in conjunction with either spontaneous or amphetamine-related movement are not faithfully represented in $\mathrm{SNr}$.

The complexity of the $\mathrm{SNr}$ response to amphetamine is a likely reflection of the complex properties and organization of SNr neurons. Unlike striatal output cells, which are silent in the absence of excitatory input, $\mathrm{SNr}$ neurons discharge at roughly the same rate whether excitatory input is present or not. In fact, activity remains relatively stable even during DA receptor blockade in awake animals (Degos et al, 2005). Adjustments in the $\mathrm{SNr}$ autoactive rate depend instead on fluctuations in the level of inhibitory GABA input, which may arise from several sources including axon collaterals of SNr projection neurons (Fallon and Loughlin, 1995; Gulacsi et al, 2003; Rick and Lacey, 1994). It is difficult to determine, therefore, if a particular pattern of striatal activity is faithfully represented in SNr. Functionally, moreover, motor-related inhibitions of $\mathrm{SNr}$ activity are relatively brief events that may correspond to movement onset followed by more prolonged excitations even as movement continues. Thus, without precise monitoring of cell firing time-locked to the activity of specific muscle groups, the role of $\mathrm{SNr}$ in drug-induced movement is difficult to characterize. Another consideration is that rather than changing the overall level of $\mathrm{SNr}$ activity, amphetamine may alter SNr firing in a context-dependent manner. In rats working for sucrose reinforcement, for example, a dose of amphetamine that activated behavior without impairing performance had no effect on the pattern of the $\mathrm{SNr}$ response, but significantly altered the relative magnitude of the neuronal change in relation to specific components of the operant task (Gulley et al, 2002a). Context also appears critical for $\mathrm{SNr}$ involvement in normal, non-drug-related movement (Handel and Glimcher, 2000). Further research is needed to assess how striatal information is integrated into ongoing $\mathrm{SNr}$ activity.

\section{Striatal Neuronal Changes Induced by Cocaine}

Although cocaine blocks DA transport and amphetamine exerts a more complex action that includes reversed DA transport and vesicular DA diffusion, both drugs elevate the synaptic level of DA (Sulzer et al, 2005). Like amphetamine, moreover, cocaine has dose-dependent effects on motor activation patterns. Thus, it should come as no surprise that systemically injected cocaine also has a predominately excitatory effect on striatal neurons in behaving rats and that this effect is blocked by a DA receptor antagonist (White et al, 1998). Differences, however, are also apparent. Although amphetamine inhibited some neurons, especially during the expression of focused stereotypy according to the behavioral response properties of individual units (see above), cocaine activated all recorded units throughout the behavioral response. This was the case at either 20 or $40 \mathrm{mg} /$ $\mathrm{kg}$ cocaine (s.c.), despite a more focused behavioral response at the higher dose. In an interesting parallel, the pattern of activation of c-Fos, an immediate-early gene, is widespread in the striatum after cocaine but limited to discrete regions after amphetamine (Graybiel et al, 1990). It is also interesting that despite similarities in the overall motor pattern induced by these drugs, there are differences in the frequency and expression of individual responses. Thus, although any link between psychostimulant-induced 
changes in striatal firing pattern and c-Fos induction is far from clear, both measures are likely indicators of the neuronal mechanisms underlying differences in the behavioral effects of these drugs.

The neuronal action of cocaine is further complicated by evidence that many of the addictive properties of this drug appear to be independent of DA. For example, the euphoria induced by cocaine in experienced users is resistant to DA receptor blockade (Sherer et al, 1989), and mice lacking the DA transporter show both self-administration behavior and conditioned place preference to cocaine (Rocha et al, 1998; Sora et al, 1998). It is interesting, therefore, that iontophoresis of cocaine in alert rats inhibits striatal neurons, but unlike amphetamine iontophoresis, this inhibitory response is not blocked by DA receptor antagonists (Kiyatkin and Rebec, 2000). Because cocaine also disrupts serotonin (5-HT) transport, at least some of the striatal action of this drug may involve an increase in striatal 5-HT. In fact, systemic injection of 3,4-methylenedioxy-methamphetamine (MDMA or ecstasy), an amphetamine derivative with a potent 5-HT-releasing action, increases both behavioral activity and striatal firing rate in rats, and these effects are blocked by $5-\mathrm{HT}$ antagonists (Ball and Rebec, 2005).

Of course, cocaine is a local anesthetic (Catterall and Mackie, 1996), and indeed, iontophoresis of procaine, a local anesthetic with minimal effects on DA transport (Ritz et al, 1987), mimics the neuronal effects of cocaine. It is also interesting that after a single intravenous (i.v.) injection of $1.0 \mathrm{mg} / \mathrm{kg}$, cocaine approaches a concentration in brain of $26 \mu \mathrm{M}$ (Fowler et al, 1998), which is above the limit for interfering with $\mathrm{Na}^{+}$transport (Reith et al, 1986). Although the inhibitory effects of both drugs occurred without a change in spike amplitude or spike duration, both of which are common indicators of local anesthetic effects, a disruption of $\mathrm{Na}^{+}$transport cannot be ruled out (Kiyatkin and Rebec, 2000). At low iontophoretic doses (5-40 nA), neuronal activity may decline without a change in spike waveform. In fact, when higher ejection currents were used, spike waveform changes became common. Thus, although a local anesthetic action of systemic cocaine on striatal neurons is possible but still speculative, it is likely that a change in DA transmission alone cannot explain the ability of this drug to interfere with striatal activity. Further support comes from evidence that blockade of striatal DA transport by i.v. cocaine occurs several minutes after maximal behavioral activation in rats (Kiyatkin et al, 2000).

\section{CONCLUSIONS}

The processing of behaviorally relevant information in striatal neurons is shaped by a complex interaction of statedependent afferent input and intrinsic membrane properties. Although DA is a key afferent, it seems designed to modulate the excitatory drive of the corticostriatal GLU system, which itself is balanced by an inhibitory GABA network. Downstream processing of these effects is further complicated by multiple mechanisms of control of $\mathrm{SNr}$ activity. Thus, within the basal ganglia, the motor-activating effects of psychostimulants must be considered within the context of ongoing neurophysiological and neurochemical responses. A drug-induced change in DA, therefore, is not likely to overwhelm GLU or GABA, but rather to alter the parameters in which these and perhaps other transmitters operate. In the striatum, this alteration is the key mechanism underlying the motor activation induced by psychostimulants.

\section{ACKNOWLEDGEMENTS}

Preparation of this manuscript and the research described in specified articles was supported by the National Institute on Drug Abuse (R01 DA 02451, R01 DA 012964, and P50 DA 05312). The assistance of Faye Caylor in formatting and organizing reference material is gratefully acknowledged.

\section{REFERENCES}

Aldridge JW, Berridge KC, Herman M, Zimmer L (1993). Neuronal coding of serial order: syntax of grooming in the neostriatum. Psychol Sci 4: 391-395.

Apicella P, Scarnati E, Schultz W (1991). Tonically discharging neurons of monkey striatum respond to preparatory and rewarding stimuli. Exp Brain Res 84: 672-675.

Ball KT, Rebec GV (2005). Role of 5- $\mathrm{HT}_{2 \mathrm{~A}}$ AND $5-\mathrm{HT}_{2 \mathrm{C} / \mathrm{B}}$ receptors in the acute effects of 3,4-methylenedioxymethamphetamine (MDMA) on striatal single-unit activity and locomotion in freely moving rats. Psychopharmacology (Berlin) 181: 676-687.

Calabresi P, Misgeld U, Dodt HU (1987). Intrinsic membrane properties of neostriatal neurons can account for their low level of spontaneous activity. Neuroscience 20: 293-303.

Carelli RM (2004). Nucleus accumbens cell firing and rapid dopamine signaling during goal-directed behaviors in rats. Neuropharmacology 47(Suppl 1): 180-189.

Carelli RM, West MO (1991). Representation of the body by single neurons in the dorsolateral striatum of the awake, unrestrained rat. J Comp Neurol 309: 231-249.

Catterall W, Mackie K (1996). Local anesthetics. In: Hardman JG, Limbird LE (eds). Goodman and Gilman's The Pharmacological Basis of Therapeutics, 9th edn. McGraw: New York. pp 331-347.

Chang HT, Wilson CJ (1990). Anatomical analysis of electrophysiologically characterized neurons in the rat striato-pallidal system. In: Bjorklund A, Hokfelt T, Wouterlood FG, van den Pol AN (eds). Handbook of Chemical Neuroanatomy, Analysis of Neuronal Microcircuits and Synaptic Interactions. Elsevier: Amsterdam. Vol. 8, pp 351-402.

Degos B, Deniau J-M, Thierry A-M, Glowinski J, Pezard L, Maurice N (2005). Neuroleptic-induced catalepsy: electrophysiological mechanisms of functional recovery induced by high frequency stimulation of the subthalamic nucleus. J Neurosci 25: 7687-7696.

DeLong MR (1990). Primate models of movement disorders of basal ganglia origin. Trends Neurosci 13: 281-285.

Deniau JM, Hammond C, Riszk A, Feger J (1978). Electrophysiological properties of identified output neurons of the rat substantia nigra (pars compacta and pars reticulata): evidence for the existence of branched neurons. Exp Brain Res 32: 409-422.

Fallon JH, Loughlin SE (1995). Substantia nigra. In: Paxinos G (eds). The Rat Nervous System, 2nd edn. Academic Press: San Diego, CA. pp 215-237.

Flaherty AW, Graybiel AM (1991). Corticostriatal transformations in the primate somatosensory system - projections from physiologically mapped body-part representations. J Neurophysiol 66: 1249-1263. 
Fowler JS, Volkow ND, Logan J, Gatley SJ, Pappas N, King P et al (1998). Measuring dopamine transporter occupancy by cocaine in vivo: radiotracer considerations. Synapse 28: 111-116.

Gardiner TW, Kitai ST (1992). Single-unit activity in the globus pallidus and neostriatum of the rat during performance of a trained head movement. Exp Brain Res 88: 517-530.

Garris PA, Rebec GV (2002). Modeling fast dopamine neurotransmission in the nucleus accumbens during behavior. Behav Brain Res 137: 47-63.

Graybiel AM, Moratalla R, Robertson HA (1990). Amphetamine and cocaine induce drug-specific activation of the c-fos gene in striosome-matrix compartments and limbic subdivisions of the striatum. Proc Natl Acad Sci USA 87: 6912-6916.

Groenewegen HJ, Berendse HW, Haber SN (1993). Organization of the output of the ventral striatopallidal system in the rat: ventral pallidal efferents. Neuroscience 57: 113-142.

Groenewegen HJ, Wright CI, Beijer AVJ (1996). The nucleus accumbens: gateway for limbic structures to reach the motor system? In: Holstege G, Brandler R, Saper CB (eds). Emotional Motor System, Progress in Brain Research. Elsevier: Amsterdam. Vol. 107, pp 485-511.

Groves PM (1983). A theory of the functional organization of the neostriatum and the neostriatal control of voluntary movement. Brain Res Rev 5: 109-132.

Groves PM, Rebec GV, Harvey JA (1975). Alteration of the effects of (+)-amphetamine on neuronal activity in the striatum following lesions of the nigrostriatal bundle. Neuropharmacology 14: 369-376.

Gulacsi A, Lee CR, Sik A, Viitanen T, Kaila K, Tepper JM et al (2003). Cell type-specific differences in chloride-regulatory mechanisms and $\operatorname{GABA}(\mathrm{A})$ receptor-mediated inhibition in rat substantia nigra. J Neurosci 23: 8237-8246.

Gulley JM, Kosobud AEK, Rebec GV (2002a). Amphetamine inhibits behavior-related neuronal responses in substantia nigra pars reticulata of rats working for sucrose reinforcement. Neurosci Lett 322: 165-168.

Gulley JM, Kosobud AEK, Rebec GV (2002b). Behavior-related modulation of substantia nigra pars reticulata neurons in rats performing a conditioned reinforcement task. Neuroscience 111: 337-349.

Gulley JM, Reed JL, Kuwajima M, Rebec GV (2004). Amphetamineinduced behavioral activation is associated with variable changes in basal ganglia output neurons recorded from awake, behaving rats. Brain Res 1012: 108-118.

Handel A, Glimcher PW (2000). Contextual modulation of substantia nigra pars reticulata neurons. J Neurophysiol 83: 3042-3048.

Hansen EL, McKenzie GM (1979). Dexamphetamine increases striatal neuronal firing in freely moving rats. Neuropharmaco$\log y$ 18: 547-552.

Haracz JL, Tschanz JT, Wang Z, Griffith KG, Rebec GV (1998). Amphetamine effects on striatal neurons: implications for models of dopamine function. Neurosci Biobehav Rev 22: 613-622.

Haracz JL, Tschanz JT, Wang Z, White IM, Rebec GV (1993). Striatal single-unit responses to amphetamine and neuroleptics in freely moving rats. Neurosci Biobehav Rev 17: 1-12.

Heimer L, Zahm DS, Alheid GF (1995). Basal ganglia. In: Paxinos G (ed). The Rat Nervous System, 2nd edn. Academic Press: San Diego. pp 579-628.

Hikosaka O, Sakamoto M, Miyashita N (1993). Effects of caudate nucleus stimulation on substantia nigra cell activity in monkey. Exp Brain Res 95: 457-472.

Hikosaka O, Sakamoto M, Usui S (1989). Functional properties of monkey caudate neurons I. Activities related to saccadic eye movement. J Neurophysiol 61: 780-798.

Juraska JM, Wilson CJ, Groves PM (1977). The substantia nigra of the rat: a Golgi study. J Comp Neurol 172: 585-600.
Kimura M (1990). Behaviorally contingent property of movementrelated activity of the primate putamen. J Neurophysiol 63: 1277-1296.

Kita H, Nambu A, Kaneda K, Tachibana Y, Takada M (2004). Role of ionotropic glutamatergic and GABAergic inputs on the firing activity of neurons in the external pallidum in awake monkeys. $J$ Neurophysiol 92: 3069-3084.

Kiyatkin EA, Kiyatkin DE, Rebec GV (2000). Phasic inhibition of dopamine uptake in nucleus accumbens induced by intravenous cocaine in freely behaving rats. Neuroscience 98: 729-741.

Kiyatkin EA, Rebec GV (1996). Dopaminergic modulation of glutamate-induced excitations of neurons in the neostriatum and nucleus accumbens of awake, unrestrained rats. J Neurophysiol 75: 142-153.

Kiyatkin EA, Rebec GV (1997). Iontophoresis of amphetamine in the neostriatum and nucleus accumbens of awake, unrestrained rats. Brain Res 771: 14-24.

Kiyatkin EA, Rebec GV (1999a). Modulation of striatal neuronal activity by glutamate and GABA: iontophoresis in awake, unrestrained rats. Brain Res 822: 88-106.

Kiyatkin EA, Rebec GV (1999b). Striatal neuronal activity and responsiveness to dopamine and glutamate after selective blockade of D1 and D2 dopamine receptors in freely moving rats. J Neurosci 19: 3594-3609.

Kiyatkin EA, Rebec GV (2000). Dopamine-independent action of cocaine on striatal and accumbal neurons. Eur J Neurosci 12: $1789-1800$.

Le Moal M (1995). Mesocorticolimbic dopaminergic neurons: functional and regulatory roles. In: Bloom FE, Kupfer DJ (eds). Psychopharmacology: The Fourth Generation of Progress. Raven Press: New York. pp 283-294.

Martin LP, Waszczak BL (1996). Dopamine D-2 receptor-mediated modulation of the GABAergic inhibition of substantia nigra pars reticulata neurons. Brain Res 729: 156-169.

McGeorge AJ, Faull RLM (1989). The organization of the projection from the cerebral cortex to the striatum in the rat. Neuroscience 29: 503-537.

Mink JW (1996). The basal ganglia: focused selection and inhibition of competing motor programs. Prog Neurobiol 50: 381-425.

Mogenson GJ, Brudzynski S, Wu M, Yang C, Yim C (1993). From motivation to action: a review of dopaminergic regulation of limbicnucleus accumbensventral pallidumpedunculopontine nucleus circuitries involved in limbic-motor integration. In: Kalivas PW, Barnes CD (eds). Limbic Motor Circuits and Neuropsychiatry. CRC Press: Boca Raton, FL. pp 193-263.

Nicola SH, Kombian SB, Malenka RC (1996). Psychostimulants depress excitatory synaptic transmission in the nucleus accumbens via presynaptic D1-like dopamine receptors. J Neurosci 16: 1591-1604.

Parent A, Hazrati LN (1995). Functional anatomy of the basal ganglia. 1. The cortico-basal ganglia-thalamo-cortical loop. Brain Res Rev 20: 91-127.

Parent A, Cote PY, Lavoie B (1995). Chemical anatomy of primate basal ganglia. Prog Neurobiol 46: 131-197.

Pennartz CM, Groenewegen HJ, Lopes da Silva FH (1994). The nucleus accumbens as a complex of functionally distinct neuronal ensembles: an integration of behavioral, electrophysiological and anatomical data. Prog Neurobiol 42: 719-761.

Pierce RC, Kumaresan V (2006). The mesolimbic dopamine system: the final common pathway for the reinforcing effect of drugs of abuse? Neurosci Biobehav Rev 30: 215-238.

Pierce RC, Rebec GV (1995). Iontophoresis in the neostriatum of awake, unrestrained rats: differential effects of dopamine, glutamate, and ascorbate on motor- and nonmotor-related neurons. Neuroscience 67: 313-324. 
Porrino LJ, Lyons D (2000). Orbital and medial prefrontal cortex and psychostimulant abuse: studies in animal models. Cereb Cortex 10: 326-333.

Rebec GV (1998). Behavioral pharmacology of amphetamines. In: Tarter RE, Ammerman RT, Ott PJ (eds). Handbook of Substance Abuse: Neurobehavioral Pharmacology. Plenum Press: New York. pp 515-527.

Rebec GV, Bashore TR (1984). Critical issues in assessing the behavioral effects of amphetamine. Neurosci Biobehav Rev 8: 153-159.

Rebec GV, Sun WL (2005). Neuronal substrates of relapse to cocaine-seeking behavior: role of prefrontal cortex. J Exp Anal Behav 84: 653-666.

Rebec GV, Christensen JRC, Guerra C, Bardo MT (1997a). Regional and temporal differences in dopamine efflux in the nucleus accumbens during free-choice novelty. Brain Res 776: 61-67.

Rebec GV, White IM, Puotz JK (1997b). Responses of neurons in dorsal striatum during amphetamine-induced focused stereotypy. Psychopharmacology 130: 343-351.

Reith ME, Kim SS, Lajtha A (1986). Structural requirements for cocaine congeners to interact with $\left[{ }^{3} \mathrm{H}\right]$ batrachotoxinin A 20alpha-benzoate binding sites on sodium channels in mouse brain synaptosomes. J Biol Chem 261: 7300-7305.

Rick CE, Lacey MG (1994). Rat substantia nigra pars reticulata neurones are tonically inhibited via $\mathrm{GABA}_{\mathrm{A}}$, but not $\mathrm{GAB}_{\mathrm{AB}}$, receptors in vitro. Brain Res 659: 133-137.

Ritz MC, Lamb RJ, Goldberg SR, Kuhar MJ (1987). Cocaine receptors on dopamine transporters are related to self-administration of cocaine. Science 237: 1219-1223.

Rocha BA, Fumagalli F, Gainetdinov RR, Jones SR, Ator R, Giros B et al (1998). Cocaine self-administration in dopamine-transporter knockout mice. Nat Neurosci 1: 132-137 (Erratum in: Nat Neurosci 1998; 1: 330).

Rosa-Kenig A, Puotz JK, Rebec GV (1993). Involvement of D1 and D2 dopamine receptors in amphetamine-induced changes in striatal activity in behaving rats. Brain Res 619: 347-351.

Ryan LJ, Young SJ, Segal DS, Groves PM (1989). Antidromically identified striatonigral projection neurons in the chronically implanted behaving rat: relations of cell firing to amphetamineinduced behaviors. Behav Neurosci 103: 3-14.

Sandstrom MI, Rebec GV (2003). Characterization of striatal activity in conscious rats: contribution of NMDA and AMPA/ kainate receptors to both spontaneous and glutamate-driven firing. Synapse 47: 91-100.

Segal DS, Janowsky DS (1978). Psychostimulant-induced behavioral effects: possible models of schizophrenia. In: Lipton MA, DiMascio A, Killam KF (eds). Psychopharmacology: A Generation of Progress. Raven Press: New York. pp 1113-1123.

Segal DS, Kuczenski R (1994). Behavioral pharmacology of amphetamine. In: Cho A, Segal DS (eds). Amphetamine and its Analogs. Academic Press: San Diego, CA. pp 115-150.

Selemon LD, Goldman-Rakic PS (1985). Longitudinal topography and interdigitation of corticostriatal projections in the rhesus monkey. J Neurosci 5: 776-794.

Servan-Schreiber D, Printz H, Cohen JD (1990). A network model of catecholamine effects: gain, signal-to-noise ratio, and behavior. Science 249: 892-895.
Sherer MA, Kumor KM, Jaffe JH (1989). Effects of intravenous cocaine are partially attenuated by haloperidol. Psychiatry Res 27: 117-125.

Shi LH, Luo F, Woodward DJ, Chang JY (2004). Neural responses in multiple basal ganglia regions during spontaneous and treadmill locomotion tasks in rats. Exp Brain Res 157: 303-314.

Smith AD, Bolam JP (1990). The neural network of the basal ganglia as revealed by the study of synaptic connections of identified neurones. Trends Neurosci 13: 259-265.

Sora I, Wichems C, Takahashi N, Li XF, Zeng Z, Revay R et al (1998). Cocaine reward models: conditioned place preference can be established in dopamine- and in serotonin-transporter knockout mice. Proc Natl Acad Sci USA 95: 7699-7704.

Sulzer D, Sonders MS, Poulsen NW, Galli A (2005). Mechanisms of neurotransmitter release by amphetamines: a review. Prog Neurobiol 75: 406-433.

Tepper JM, Koos T, Wilson CJ (2004). GABAergic microcircuits in the neostriatum. Trends Neurosci 27: 662-669.

Tschanz JT, Griffith KE, Haracz JL, Rebec GV (1994). Cortical lesions attenuate the opposing effects of amphetamine and haloperidol on neostriatal neurons in freely moving rats. Eur J Pharmacol 257: 161-167.

Uzwiak AJ, Guyette FX, West MO, Peoples LL (1997). Neurons in accumbens subterritories of the rat: phasic firing time-locked within seconds of intravenous cocaine self-infusion. Brain Res 767: 363-369.

Waszczak BL, Walters JR (1983). Dopamine modulation of the effects of gamma-aminobutyric acid on substantia nigra pars reticulata neurons. Science 220: 218-221.

West MO, Carelli RM, Pomerantz M, Cohen SM, Gardner JP, Chapin JK et al (1990). A region in the dorsolateral striatum of the rat exhibiting single-unit correlations with specific locomotor limb movements. J Neurophysiol 64: 1233-1246.

West MO, Peoples LL, Michael AJ, Chapin JK, Woodward DJ (1997). Low-dose amphetamine elevates movement-related firing of rat striatal neurons. Brain Res 745: 331-335.

White IM, Doubles L, Rebec GV (1998). Cocaine-induced activation of striatal neurons during focused stereotypy in rats. Brain Res 810: 146-152.

Wightman RM, Zimmerman JB (1990). Control of dopamine extracellular concentration in rat striatum by impulse flow and uptake. Brain Res Rev 15: 135-144.

Wilson CJ (1993). The generation of natural firing patterns in neostriatal neurons (chemical signalling in the basal ganglia). Prog Brain Res 99: 277-297.

Wilson CJ, Groves PM (1981). Spontaneous firing patterns of identified spiny neurons in the rat neostriatum. Brain Res 220: 67-80.

Wilson CJ, Kawaguchi Y (1996). The origins of two-state spontaneous membrane potential fluctuations of neostriatal spiny neurons. J Neurosci 16: 2397-2410.

Wood DA, Rebec GV (2004). Dissociation of core and shell singleunit activity in the nucleus accumbens in free-choice novelty. Behav Brain Res 152: 59-66.

Woodward DJ, Chang JY, Janak P, Azarov A, Anstrom K (2000). Activity patterns in mesolimbic regions in rats during operant tasks for reward. Prog Brain Res 126: 303-322. 